\title{
SENSITIVITY ANALYSIS OF SNOW COVER TO CLIMATE CHANGE SCENARIOS AND THEIR IMPACT ON PLANT HABITATS IN ALPINE TERRAIN
}

\author{
FRANZISKA KELLER, STÉPHANE GOYETTE and MARTIN BENISTON \\ Department of Geosciences, Geography, Fribourg, Switzerland \\ E-mail: Franziska.Keller@fal.admin.ch
}

\begin{abstract}
In high altitude areas snow cover duration largely determines the length of the growing season of the vegetation. A sensitivity study of snow cover to various scenarios of temperature and precipitation has been conducted to assess how snow cover and vegetation may respond for a very localized area of the high Swiss Alps (2050-2500 m above sea level). A surface energy balance model has been upgraded to compute snow depth and duration, taking into account solar radiation geometry over complex topography. Plant habitat zones have been defined and 23 species, whose photoperiodic preferences were documented in an earlier study, were grouped into each zone.

The sensitivity of snowmelt to a change in mean, minimum and maximum temperature alone and a change in mean temperature combined with a precipitation change of $+10 \%$ in winter and $-10 \%$ in summer is investigated. A seasonal increase in the mean temperature of 3 to $5 \mathrm{~K}$ reduces snow cover depth and duration by more than a month on average. Snow melts two months earlier in the rock habitat zone with the mean temperature scenario than under current climate conditions. This allows the species in this habitat to flower earlier in a warmer climate, but not all plants are able to adapt to such changes.
\end{abstract}

\section{Introduction}

In alpine terrain, the distribution of snow and vegetation are closely linked. The topography allows a variety of microhabitats to exist as a result of particular microclimatic conditions. These are modulated to a large extent by the solar energy input, which is itself influenced by local topography, in particular slope angle and orientation (Fischer, 1990; Guisan et al., 1998; Horsch, 2003). Plant species in these areas exhibit specific micro-environmental requirements that are mostly affected by the duration of snow cover but also by relief (Körner, 1995; Körner, 1999). Microhabitats are certainly key factors affecting the plant diversity of high mountains and species can be clearly differentiated according to their micro-topographical niches (Gottfried et al., 1998; Gottfried et al., 1999). According to Grabherr et al. (1995) at least one-third of the alpine/nival flora of the Alps is restricted to azonal habitats, especially rocks, scree, and snowbeds which represent abnormal habitats created by disturbances (Grabherr et al., 1995). For example, plants in snowbeds, i.e., hollows with a long-lying snow cover, receive an effective protection against low temperatures in winter. Following snowmelt, the water availability in a snowbed is improved but the soil organic matter content and the nutrient availability is reduced 
(Billings and Bliss, 1959; Galen and Stanton, 1995). Plant species such as Sibbaldia procumbens, Veronica alpina and others are well adapted to such conditions as shown by a study of Galen and Stanton (1995) in the Pennsylvania Mountain Park, U.S.A., but there are other alpine species which are not (for example Loiseleuria procumbens).

The patterns of snow distribution in rugged alpine terrain are the most visible consequence of topography and its interaction with climatic variables like radiation, precipitation and wind (Körner, 1992; Gottfried et al., 1999; Körner, 1999). In order to adequately simulate the snow distribution in such regions, a model with a very high spatial resolution is required. However, there are computational limits to the application of such models (Beniston et al., 1997). General Circulation Models (GCMs) and Regional Circulation Models (RCMs) work with grid cells too large to reflect patterns relevant for snow-plant interactions. On the other hand, surface energy balance models (SEBM), although not representing the 3-D atmospheric circulation patterns, are able to simulate locally the energy and water budgets. With the help of such a model, it is possible to assess the change in snow cover duration in response to climatic change scenarios (Beniston et al., 2003b; Keller and Goyette, accepted).

Since the beginning of the 20th century a positive trend in global-average annual temperature has been observed (0.3-0.7 K; Jones and Moberg, 2003) with more pronounced changes in some regions. In the Swiss Alps, for instance, the increase of the average annual temperature over the 20th century reached $1.5 \mathrm{~K}$ in certain locations (Beniston et al., 1997). A clear difference in behavior of minimum and maximum temperatures that depends on altitude and location could be observed for Switzerland (Jungo and Beniston, 2001). The predictions for future global temperature increase range from 1.4 to $5.8 \mathrm{~K}$ for the end of the 21 st century (IPCC, 2001). For the Swiss Alps, Giorgi and Francisco (2000) estimate a temperature increase of $2-4 \mathrm{~K}$ and a precipitation increase in winter of $10 \%$ and a decrease in summer of $10 \%$.

The vegetation at high altitudes is believed to be particularly sensitive to longterm climate change because abiotic factors, especially climate, dominate with respect to biotic interactions (Körner, 1994; Grabherr et al., 1995; Beniston et al., 1996; Theurillat and Guisan, 2001). At these elevations, effects of anthropogenic land use change are mostly negligible and many high alpine species grow slowly and are long-lived. Therefore, significant changes of vegetation patterns are not likely to be caused by short-term climatic fluctuations, but may become obvious as a result of long-term climate change (Pauli et al., 1999).

Recently, a study showed that the development of alpine plants is not only a function of temperature change but is also sensitive to day length at the beginning of the growing period (Keller and Körner, 2003). The moment of snowmelt determines the day length experienced by the plants at the beginning of the growing season; hence the timing of snowmelt is crucial for the vegetation cycle of the species (Körner, 1992). 
This study focuses on the simulation of the change in timing of snowmelt on a $500 \times 500 \mathrm{~m}^{2}$ surface in the Swiss Alps. The following questions are addressed:

- How will the dates of snowmelt change very locally in a rugged terrain with an increase in the mean, minimum and maximum temperatures and a shift in precipitation?

- What impact will this have on the plant habitats?

The separation into mean, minimum and maximum temperature scenarios was investigated because vegetation and snow exhibit different sensitivities to each of these components of the diurnal temperature cycle (Körner and Larcher, 1988).

\section{Methods}

\subsection{STUDY SITE AND CLIMATIC DATA}

The study site is located on the southwestern slope of the Säntis, a summit in the eastern part of Switzerland ( $2490 \mathrm{~m}$ above sea level, $\left.9^{\circ} 20^{\prime} \mathrm{E} ; 47^{\circ} 15^{\prime} \mathrm{N}\right)$. This site accommodates a weather station, which provides the necessary input data for the numerical simulations as well as for the analysis. The observations of air temperature, precipitation, wind, snow depth, surface pressure, incoming solar radiation and dew point temperature are compiled by Meteo Swiss on the basis of measurements made by the automated weather station network ANETZ (Bantle, 1989). The site was chosen because of its elevation and the availability of hourly weather records. Close to this station, an area covering $500 \times 500 \mathrm{~m}^{2}$ with an elevation range of $500 \mathrm{~m}$ was selected on the basis of a digital elevation model (DEM) with a grid spacing of $25 \mathrm{~m}$ (Figure 1). This grid is then used as one of the boundary conditions in the simulation of the distribution of snowmelt using a SEBM. Details of the model structure and the experimental design are given in the Appendix.

\subsection{PLANT DATA AND ANALYSES}

The snow cover duration and the moment of snowmelt are analyzed for the following four altitudinal classes: 2050-2150, 2150-2250, 2250-2350, and 2350-2450 m above sea level. This allows a description of the general behavior of the snow cover in the four altitudinal classes and over the investigated period for the different climate change scenarios.

Over the investigated area five habitat zones for plant species are distinguished according to Grabherr et al. (1995) and Gottfried et al. (1998) as shown in Figure 2:

1. Snowbeds

2. Ridges

3. Swards (i.e. rather flat areas) 


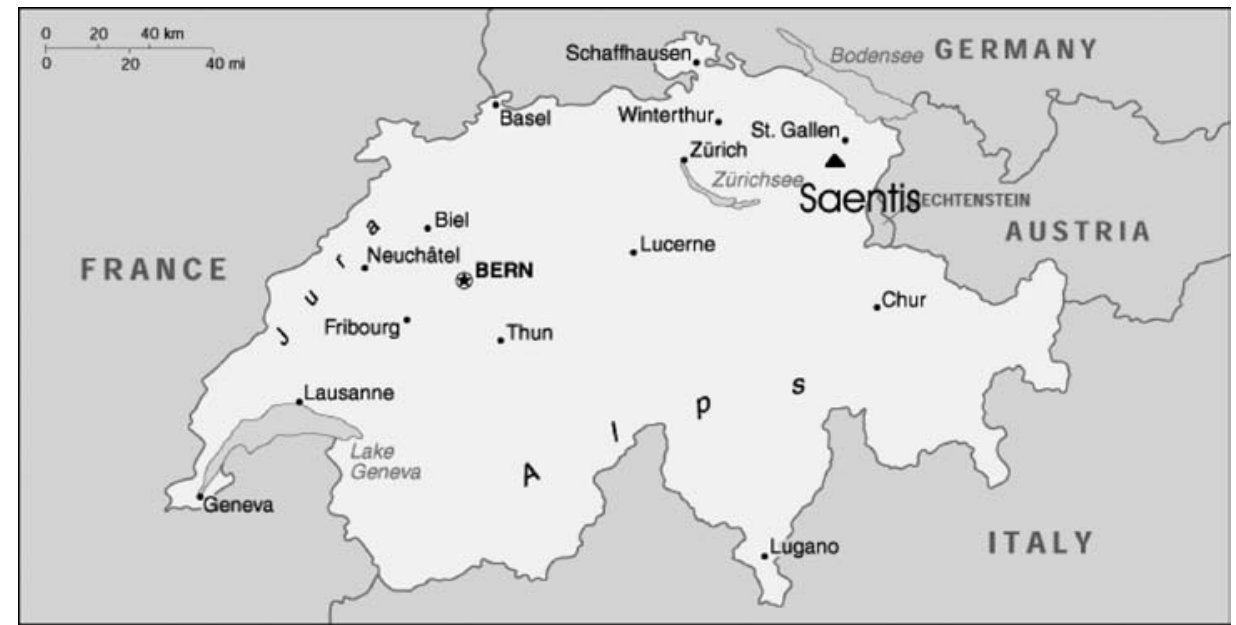

Figure 1. Location of the study area in the eastern part of Switzerland. Source: http:// www.weatherhub.com/global/sz_map.htm.

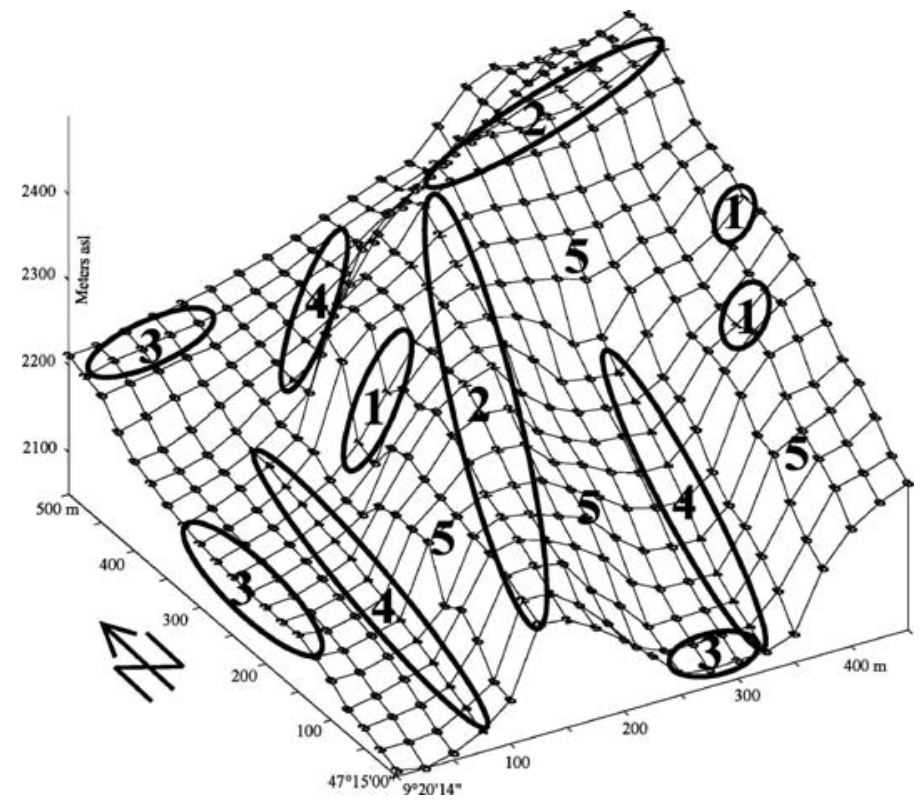

Figure 2. Habitat distribution in the investigated area. Numbers refer to: 1 snowbeds, 2 ridges, 3 sward, 4 scree zones and 5 rocky habitats. The distribution of the plant species into the different habitat zones are indicated in Table I.

\section{Scree}

5. Rocks

The digital elevation model used in this study has a resolution of $25 \mathrm{~m}$, which is rather coarse for the analysis of the microhabitats of plants, and consequently 
TABLE I

Habitat preferences of the investigated plant species combined to the results of the Keller and Körner (2003) study

\begin{tabular}{llll}
\hline Species $^{\mathrm{a}}$ & Abbreviation & Daylength $^{\mathrm{b}}$ & Habitat preferences $^{\mathrm{c}}$ \\
\hline Androsace alpina & Andr alpi & $>=14.5 \mathrm{~h}$ & 5 \\
Carex curvula & Care curv & no trend & 3 \\
Cerastium uniflorum & Cera unif & always & 4 \\
Elyna myosuroides & Elyn myos & always & 2 \\
Erigeron uniflorum & Erig unif & $<=15 \mathrm{~h}$ & 2 \\
Festuca af.intercedens & Fest inte & $>=14.5 \mathrm{~h}$ & 3 \\
Gentiana bavarica & Gent bava & no trend & 1 \\
Geum reptans & Geum rept & no trend & 3,4 \\
Gnaphalium supium & Gnap supi & $>=14.5 \mathrm{~h}$ & 1 \\
Leucanthemopsis alpina & Leuc alpi & $>=15 \mathrm{~h}$ & 3 \\
Linaria alpina & Lina alpi & $>=15 \mathrm{~h}$ & 4 \\
Luzula spicata & Luzu spic & $>=14.5 \mathrm{~h}$ & 3,4 \\
Minuartia sedoides & Minu sedo & always & 3 \\
Oxyria digyna & Oxyr digy & $>=15 \mathrm{~h}$ & 1 \\
Poa alpina & Poa alpi & always & 3 \\
Poa laxa & Poa laxa & $>=14.5 \mathrm{~h}$ & 3,5 \\
Potentilla frigida & Pote frig & $<=15 \mathrm{~h}$ & 3,5 \\
Ranunculus glacialis & Ranu glac & always & $3,4,5$ \\
Saxifraga bryoides & Saxi bryo & $>=14.5 \mathrm{~h}$ & 4,5 \\
Saxifraga oppositifolia & Saxi oppo & always & 5 \\
Saxifraga seguieri & Saxi segu & always & 4 \\
Sedum alpestre & Sedu alpe & $>=16 \mathrm{~h}$ & 3 \\
Sibbaldia procumbens & Sibb proc & $<=12 \mathrm{~h}$ & 1 \\
\hline & 3 & & \\
\hline
\end{tabular}

$1=$ snowbed, $2=$ ridges, $3=$ sward, $4=$ scree and $5=$ rock habitat zone.

${ }^{a}$ Nomenclature follows Ehrendorfer (1973).

${ }^{\mathrm{b}}$ Results from Keller and Körner (2003).

${ }^{c}$ Habitat preferences from Bahn and Körner (1987), Grabherr (1995), Lauber and Wagner (1996).

only large habitat zones in the study area are defined. The vascular plant species already examined in Keller and Körner (2003) are grouped into five azonal habitat classes according to a bibliography review (Table I). The rock zones are inserted in the model where the slopes exceed 40 degrees. Although there are more species that could grow in each of these habitat types, the investigations are limited to the species previously analyzed in Keller and Körner (2003) in order to reach further conclusions. Although high alpine plant species mostly reproduce vegetatively, flowering is still important to guarantee genetic variability, an aspect which can also contribute to adaptation to new environmental conditions. 
The snow cover for four dates during snowmelt is considered. For convenience the snow cover on 18 March, 3 April, 13 May and 21 June is analyzed; these dates correspond to the day length scenarios tested in Keller and Körner (2003), i.e., 12, $14.5,15$ and $16 \mathrm{~h}$. For every date the percentage of snow-free pixels per habitat zone is calculated. The day length preference of the species described in Keller and Körner (2003) together with the grouping into habitat zones allows the calculation of the percentage of potentially flowering species per habitat zone for each of the four investigated dates. Together with the percentage of snow-free pixels, this allows an assessment of the interspecific variations of possible reactions of the plant species to changed snowmelt patterns.

\section{Results}

\subsection{SNOW COVER SIMULATIONS}

\subsubsection{Control Run and Observations}

As already shown in Keller and Goyette (accepted), the snow depth simulated by the SEBM generally shows a good agreement with the observed snow depth data (Figure 3) for a point simulation at the level of the Säntis weather station and guarantees therefore a good validation of the model.

In the following paragraphs the evolution of the snow cover in the control run is described.

The snow depth simulated per altitudinal class increases with altitude (Figure 4). At 2350-2450 $\mathrm{m}$ above sea level more days can be counted with a snow depth $>3 \mathrm{~m}$

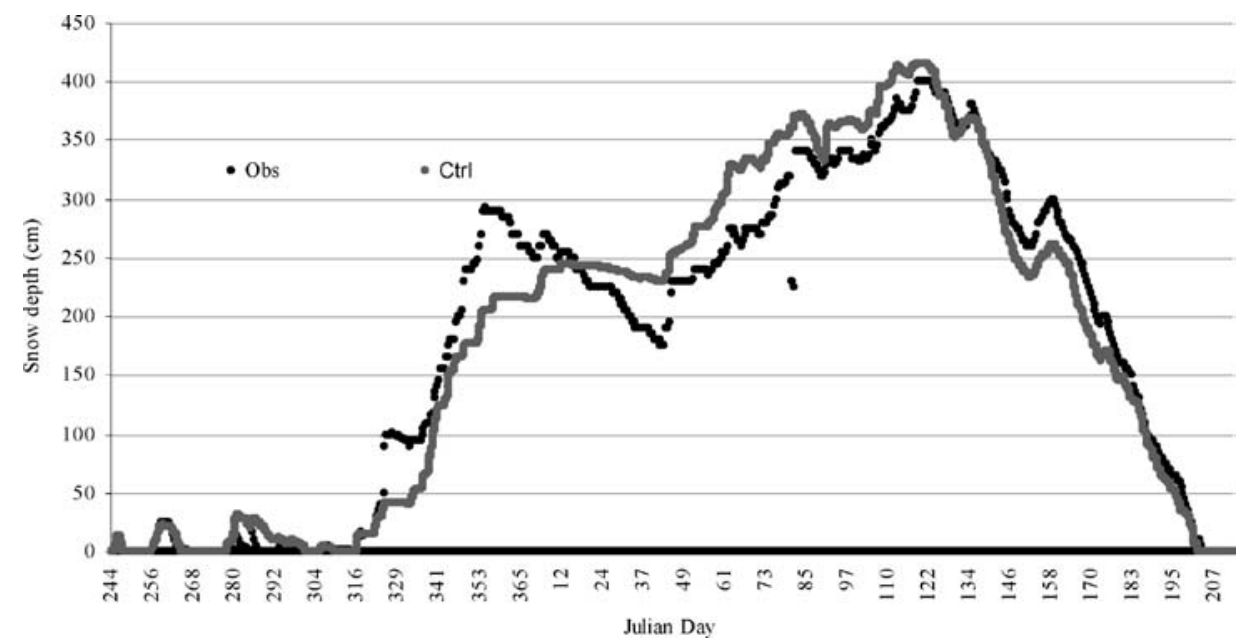

Figure 3. Model validation for Säntis $\left(2490 \mathrm{~m}\right.$ above sea level, $\left.9^{\circ} 20^{\prime} \mathrm{E} ; 47^{\circ} 15^{\prime} \mathrm{N}\right)$ : observations (obs; black dots) and the simulated snow depth for the control run (ctrl; grey dots) for September 1988 to August 1989. 

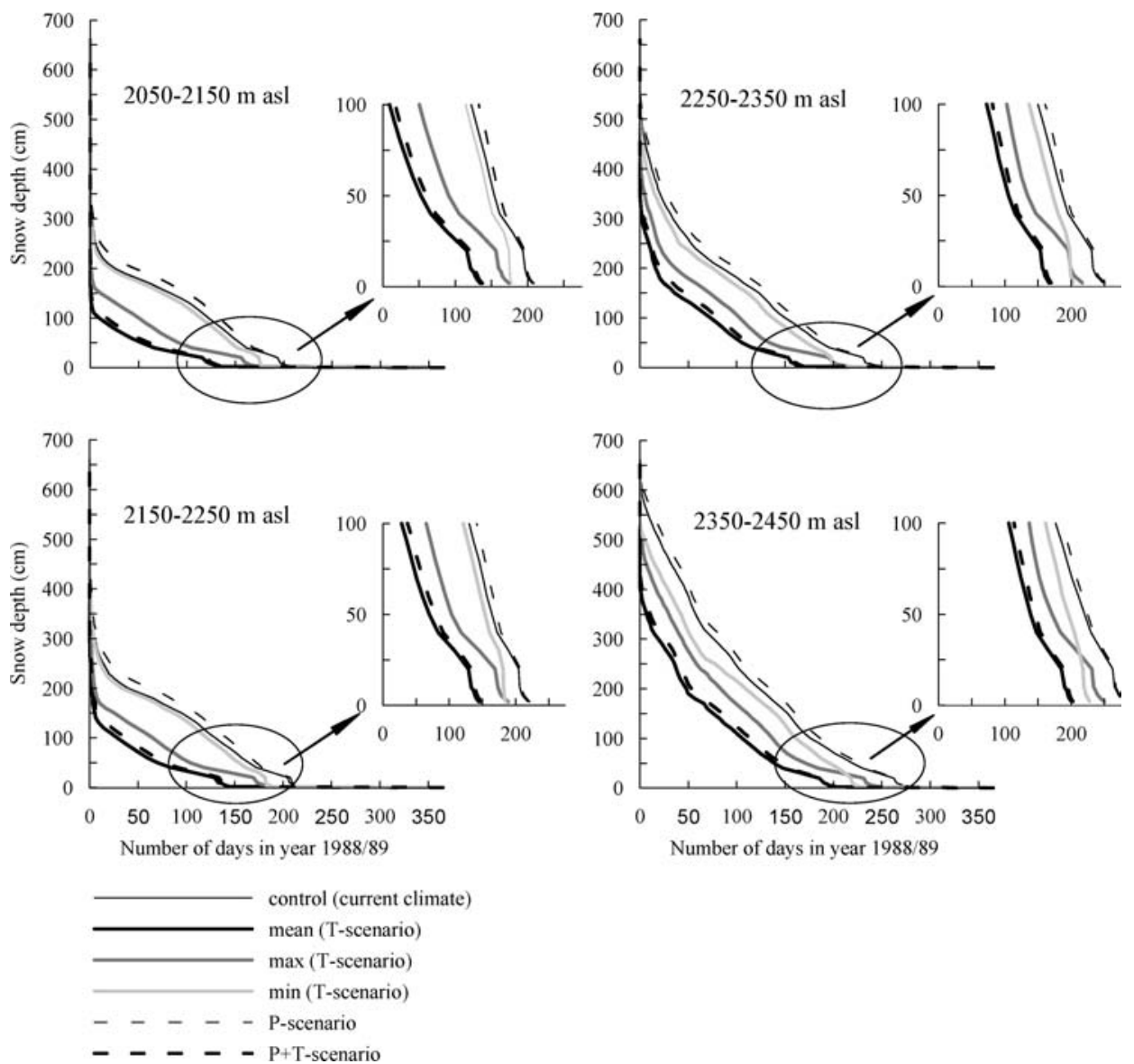

Number of days in year 1988/89

Figure 4. Frequency distributions of snow cover duration. The averaged number of days per snow depth for each of the four altitudinal classes (2050-2150, 2150-2250, 2250-2350, 2350-2450 m) in the September 1988 to August 1989 and for each climate scenario. $P=$ precipitation scenario (increase of $10 \%$ in winter, decrease of $10 \%$ in summer), $T=$ mean temperature increase scenario.

whereas at 2050-2150 m above sea level only very few days show this snow depth. Days with a shallow snow cover are also increasing with altitude.

The simulated average Julian day of the end of snowmelt can be observed later in the year for increasing altitude (Table II). The increasing standard deviation with altitude is important. This is due to the more complex relief at $2350-2450 \mathrm{~m}$ above sea level, to the orientation of the pixels either south or north and therefore to a much greater range of snow cover duration attributed to the influence of the direct solar radiation on the energy budget of the snow pack (Table III).

On 13 May, $14 \%$ of the pixels in the snowbed and the ridge area are snowfree, $28 \%$ of the scree, and $22 \%$ of the rocky habitat zones, especially in the areas 
TABLE II

Julian day when snow has melted with an indication of the standard deviation for each of the four elevation classes and scenarios

\begin{tabular}{lllllll}
\hline $\begin{array}{l}\text { Elevational } \\
\text { classes }(\mathrm{m})\end{array}$ & $\begin{array}{l}\text { Current climate } \\
\text { control }\end{array}$ & Mean & $\begin{array}{l}T \text {-scenarios } \\
\text { Min }\end{array}$ & Max & $P$-scenario & $P+T$-scenario \\
\hline $2050-2150$ & $148.4 \pm 20.9$ & $112.2 \pm 18.7$ & $135.9 \pm 10.3$ & $128.0 \pm 6.0$ & $149.1 \pm 16.7$ & $110.7 \pm 19.3$ \\
$2150-2250$ & $154.6 \pm 24.3$ & $120.5 \pm 19.0$ & $142.3 \pm 18.4$ & $134.0 \pm 16.7$ & $158.2 \pm 24.4$ & $124.0 \pm 18.3$ \\
$2250-2350$ & $170.7 \pm 37.1$ & $137.3 \pm 27.5$ & $159.2 \pm 33.3$ & $152.2 \pm 34.9$ & $174.4 \pm 37.3$ & $139.4 \pm 26.9$ \\
$2350-2450$ & $188.5 \pm 43.9$ & $159.0 \pm 43.4$ & $176.4 \pm 43.8$ & $171.0 \pm 47.8$ & $190.5 \pm 43.3$ & $160.8 \pm 44.5$ \\
\hline
\end{tabular}

Mean stands for mean, Min for minimum and Max for maximum temperature scenario.

TABLE III

Number of pixels per altitudinal class and per orientation

\begin{tabular}{lllllllll}
\hline Elevation classes $(\mathrm{m})$ & $\mathrm{N}$ & $\mathrm{NE}$ & $\mathrm{E}$ & $\mathrm{SE}$ & $\mathrm{S}$ & $\mathrm{SW}$ & $\mathrm{W}$ & $\mathrm{NW}$ \\
\hline $2050-2150$ & - & - & 4 & 8 & 20 & 33 & 19 & 1 \\
$2150-2250$ & - & - & 1 & 22 & 14 & 40 & 47 & 1 \\
$2250-2350$ & - & - & - & 11 & 12 & 27 & 32 & 15 \\
$2350-2450$ & 4 & 5 & - & - & 22 & 18 & 11 & 20 \\
Total & 4 & 5 & 5 & 41 & 68 & 118 & 109 & 37 \\
\hline
\end{tabular}

exposed to the south (Figure 5a). No snowmelt was simulated for the sward pixels (Table IV). On 21 June, parts of the snowbeds, the rocky slopes facing north and the scree zone to the north are still snow covered. On this particular date, $70 \%$ of the pixels are on average snow-free.

\subsubsection{Mean Temperature Scenario}

The mean temperature increase scenario is prescribed by a seasonally dependent increase in the mean temperatures and it shows the strongest decrease in simulated snow depth (Figure 4).

The simulated average Julian day of snowmelt decreases by 36 days for the lowest altitudinal class in comparison to the control run (Table II).

With the mean temperature scenario, the snow pack is already less abundant in March than in the control run (Figure 5b), but there are no snow-free pixels (Table IV). On 3 April, a large part of the simulated area is snow-free (53\% of the pixels; Table IV), especially in the sward and the scree habitat zone. Only the parts of the snowbeds and the rocky slopes orientated to the north are still covered with snow. By 21 June, snow has mostly melted in these areas (93\% of the pixels are snow-free). Only on the north-oriented slopes does some snow still remain, according to the model. 
a.)

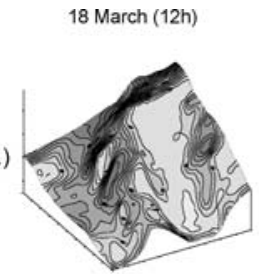

b.)

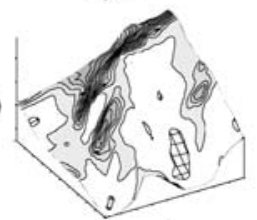

c.)

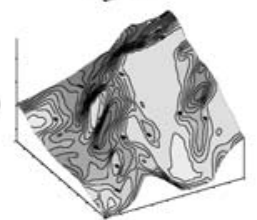

d.)
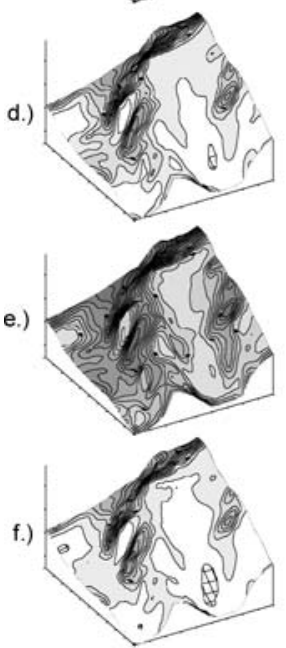

3 April (14.5h)
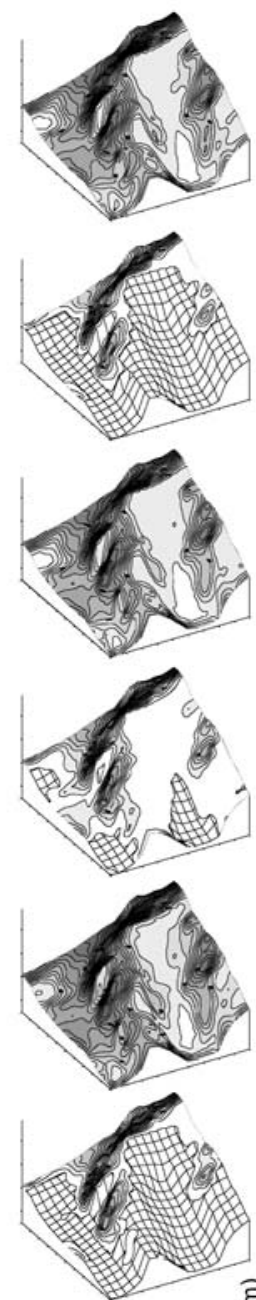

13 May (15h)
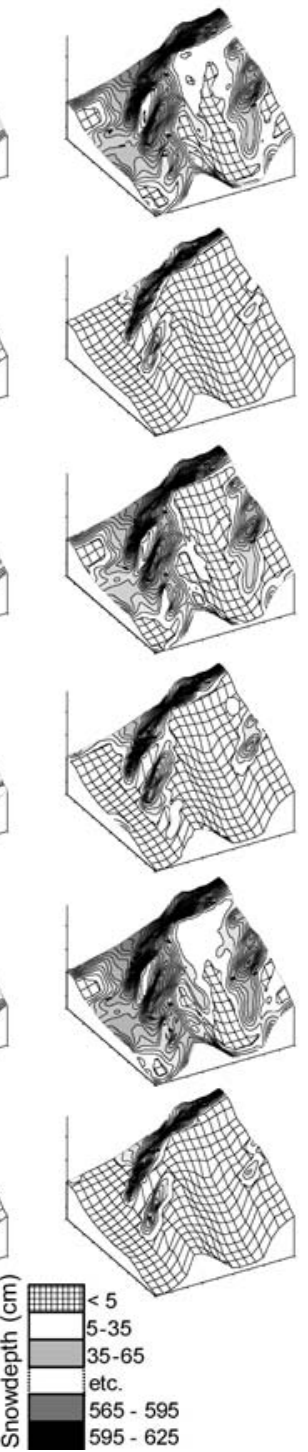

21 June (16h)
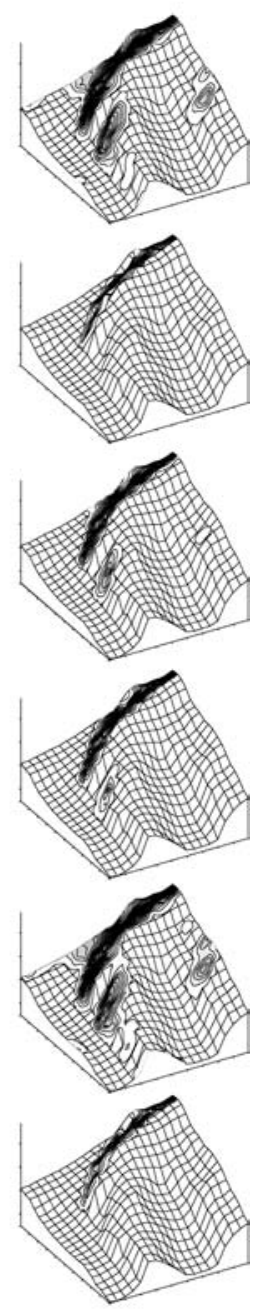

Figure 5. Evolution of the snow cover for 18 March, 3 April, 13 May and 21 June (from left to right) for the six investigated climate change scenarios (from top down). The blended contour curves from grey to black indicate the snow depth (deeper when the area is darker). The white zones indicate a snow depth of 5 to 35 centimetres, i.e. the snow, which will melt in the next days. Areas where the grid is visible have less than $5 \mathrm{~cm}$ of snow (with $5 \mathrm{~cm}$ of snow $70 \%$ of the surface is snow covered according to the snow fraction parameterisation). a) denotes the control run, b) the mean, c) the minimum, d) the maximum, e) the precipitation and f) the temperature-precipitation scenario. 
TABLE IV

Percentage of snow-free pixels per scenario for specified dates and per habitat zone

\begin{tabular}{|c|c|c|c|c|c|c|c|c|}
\hline & $\begin{array}{l}\text { Habitat } \\
\text { zone }\end{array}$ & $\begin{array}{l}\text { Current } \\
\text { Climate } \\
\text { control }\end{array}$ & Mean & $\begin{array}{l}T \text {-scenarios } \\
\text { Min }\end{array}$ & Max & $P$-scenario & $\begin{array}{l}P+T \\
\text { scenario }\end{array}$ & $\begin{array}{l}\text { Potential } \\
\text { flowering } \\
\text { species }(\%)\end{array}$ \\
\hline & snowbed & 0.0 & 0.0 & 0.0 & 0.0 & 0.0 & 0.0 & 50 \\
\hline 18 March & ridge & 0.0 & 0.0 & 0.0 & 0.0 & 0.0 & 0.0 & 100 \\
\hline \multirow[t]{4}{*}{$12 \mathrm{~h}$} & sward & 0.0 & 0.0 & 0.0 & 0.0 & 0.0 & 0.0 & 36 \\
\hline & scree & 0.0 & 0.0 & 0.0 & 0.0 & 0.0 & 0.0 & 28 \\
\hline & rock & 0.0 & 0.0 & 0.0 & 0.0 & 0.0 & 0.5 & 50 \\
\hline & snowbed & 0.0 & 28.6 & 0.0 & 0.0 & 0.0 & 28.6 & 25 \\
\hline 3 April & ridge & 0.0 & 48.8 & 0.0 & 0.0 & 0.0 & 48.8 & 100 \\
\hline \multirow[t]{4}{*}{$14.5 \mathrm{~h}$} & sward & 0.0 & 67.6 & 0.0 & 17.6 & 0.0 & 64.7 & 81 \\
\hline & scree & 0.0 & 75.0 & 0.0 & 0.0 & 0.0 & 71.9 & 71 \\
\hline & rock & 0.0 & 50.0 & 0.0 & 5.6 & 0.0 & 48.0 & 100 \\
\hline & snowbed & 14.3 & 71.4 & 14.3 & 14.3 & 14.3 & 71.4 & 25 \\
\hline 13 May & ridge & 14.0 & 72.1 & 23.3 & 25.6 & 7.0 & 69.8 & 100 \\
\hline \multirow[t]{4}{*}{$15 \mathrm{~h}$} & sward & 0.0 & 94.1 & 5.9 & 29.4 & 0.0 & 94.1 & 72 \\
\hline & scree & 28.1 & 84.4 & 31.3 & 25.0 & 28.1 & 84.4 & 71 \\
\hline & rock & 22.7 & 73.7 & 36.9 & 73.7 & 14.6 & 71.7 & 100 \\
\hline & snowbed & 57.1 & 100.0 & 71.4 & 100.0 & 42.9 & 100.0 & 75 \\
\hline 21 June & ridge & 67.4 & 93.0 & 74.4 & 88.4 & 58.1 & 93.0 & 50 \\
\hline \multirow[t]{3}{*}{$16 \mathrm{~h}$} & sward & 79.4 & 100.0 & 97.1 & 97.1 & 73.5 & 97.1 & 81 \\
\hline & scree & 75.0 & 93.8 & 84.4 & 87.5 & 75.0 & 93.8 & 71 \\
\hline & rock & 65.7 & 82.3 & 75.8 & 77.8 & 61.6 & 82.3 & 83 \\
\hline
\end{tabular}

$\mathrm{T}=$ temperature scenario, $P=$ precipitation scenario, $P+T=$ precipitation and mean temperature increase scenario. In the last column the percentage of the potential flowering species at this moment of the year and for each habitat zone are listed.

\subsubsection{Minimum Temperature Scenario}

The minimum temperature scenario is prescribed by a seasonally dependent increase in the minimum temperatures.

The minimum temperature scenario only shows an impact on the snow cover where the observed input temperatures do not decrease too much below the freezing point.

The simulated number of days with a thin snow cover (see the enlarged graphs of Figure 4) decreases slower for the minimum temperature scenario than the maximum temperature scenario and the control run. The simulated average date of snowmelt advances one third less than for the mean temperature scenario (Table II).

The spatial distribution of the evolution of the snow cover up to the beginning of April closely follows that of the control run (Figure 5c). In mid-May, the minimum temperature scenario already shows more snow-free pixels in all habitat zones 
(except in snowbed). On 21 June the rocky slopes facing north and the two taller snowbed zones are still snow-covered, although with a less deep snow pack than in the control run (80\% of pixels are snow-free; Table IV).

\subsubsection{Maximum Temperature Scenario}

The maximum temperature scenario is given by a seasonal increase of the maximum temperatures.

In all altitudinal classes the model simulates a larger number of days with a snow depth below $25 \mathrm{~cm}$.

Snowmelt occurs 20 days earlier for the lowest and 18 days for the highest altitudinal class compared to the control run (Table II). These shifts in snowmelt are larger than for the minimum temperature scenario.

The simulated spatial distribution of the snow pack and its depth show large differences in comparison to the control run and resembles the pattern of the mean temperature scenario (Figure 5d). On 3 April, the sward and the rock habitat zone already show some snow-free pixels, but elsewhere, computed snow depths range from 5 to $35 \mathrm{~cm}$. On 13 May, except for the snowbed, all zones are snow-free. On 21 June only the north-facing slope and the tallest snowbed are still partly snow covered.

\subsubsection{Precipitation Scenario}

The precipitation scenario, which consists of an increase of $10 \%$ of the winter precipitation and a $10 \%$-decrease of the summer precipitation, simulates a slightly higher number of days per snow depth than the control run (Figure 4). However, the number of snow-free days is about the same as in the control run, despite the fact that the number of days with smaller snow depth is decreasing.

The snowmelt for each altitudinal class occurs a few days later than in the control run (Table II), and the difference from the control run is much less than the calculated standard deviation for all pixels within a given altitudinal class.

The spatial pattern of snowmelt closely resembles that of the control run although there is a greater snow pack (Figure 5e). On 13 May, the first snow-free pixels appear on the south-facing rocky slopes, snowbed, ridges and sward areas. On 21 June, all habitat zones exhibit some snow-free pixels, but except for the scree area all zones show less important snowmelt than in the control run (62\% of snow-free pixels; Table IV).

\subsubsection{Temperature-Precipitation Scenario}

The temperature-precipitation scenario is constructed by a combination of the mean temperature increase scenario and the precipitation scenario as described above.

The simulated number of days per snow depth for the combined temperatureprecipitation scenario is for all altitudinal classes slightly larger than for the mean temperature scenario (Figure 4).

The average date of snowmelt decreases by 38 days at 2050-2150 m above sea level, which is a faster rate than for the mean temperature scenario (Table II). 
The spatial snowmelt pattern closely resembles that of the mean temperature scenario (Figure 5f). On 3 April all habitat zones have snow-free pixels (Table IV). In the scree and the rock habitat zone the percentage of snow-free pixels is slightly less than in the mean temperature scenario. On 21 June snow is still simulated on the north-orientated slopes.

\subsection{THE SNOW-PLANT INTERACTION}

\subsubsection{Description of Habitat Preferences of the Species Investigated}

Five habitat zones in the test area were distinguished as shown in Figure 2. A differentiation was drawn between species, which avoid disturbances (by snow and moving scree) and therefore prefer sward or rock zones. Species, which are adapted to regular disturbances, grow either on moving scree or on windswept ridges. Others, which need a deep snow cover will grow in snowbed areas. There are further species, which can grow on nearly all types of terrain (see Table I).

\subsubsection{Species Habitat and Snow Cover Changes}

The analysis of the snow cover simulations showed that depending on the scenario, snowmelt might occur up to a month earlier. The timing of snowmelt and the day length at snowmelt determine the onset of the growing season for alpine plant species. If the disappearance of snow in the habitat zones and the day length requirements for flowering of each species are compared (according to Keller and Körner, 2003), the percentage of potentially flowering species per habitat can be determined and it can be deduced whether potentially more species are able to flower when snow melts earlier in the season.

Under current climate (control) conditions, there are no snow-free pixels until 13 May in the snowbed, ridge, scree and rock zones, and no snow-free pixels in the sward zone until 21 June. The precipitation scenario closely follows the control run, with slightly fewer snow-free pixels in most habitats. The minimum temperature scenario slightly increases the percentage of snow-free pixels, while the maximum temperature scenario gives moderate increases. Large increases are produced by the mean temperature scenario, with similar increases for the temperature-precipitation scenario.

The results of this investigation highlight the fact that, in snow-free conditions, $75 \%$ of the species in the snowbed habitat zone are potentially able to flower on 21 June, while all species growing on ridges are already potentially able to flower on 18 March. $81 \%$ of the sward zone species are potentially able to flower on 3 April as well as $71 \%$ of the scree species. All species growing in the rock zone are potentially able to flower on 3 April (Table IV). All these percentages are only valid if the snow cover has already melted at these dates.

SEBM computations of the snow cover for the mean temperature scenario show that snow-free pixels occur already on 3 April in all habitat zones. The creation of 
snow-free pixels on 3 April would allow earlier flowering of $25 \%$ of species in the snowbed zone, all species in the ridge and scree zones (Table IV). Especially in sward zones, $9 \%$ more species are able to flower on 3 April compared to 13 May. The combined temperature-precipitation scenario shows the same tendencies as the mean temperature scenario.

For the maximum temperature scenario, the creation of snow-free pixels on 3 April that would allow earlier flowering of $81 \%$ of species in the sward zone and all species in the rock zone. On 13 May 14\% snow-free pixels in the snowbed habitat zone are simulated compared to the control run.

The precipitation scenario closely follows the control run, and snowmelt does not occur earlier in any of the habitat zones.

Species that flower later than the period of snowmelt will already use energy to respire and run the risk of being overgrown by other species.

\section{Discussion}

The snowmelt patterns change significantly according to the scenario. The greatest difference is observed between the control run and the mean temperature scenario, because to construct the mean temperature scenario the whole temperature curve is shifted to a higher level and thereby both the maximum and the minimum temperature values were increased. The construction of the maximum temperature scenario, however, only increases the maximum values of the temperature curve and therefore the minimum temperature values are left unchanged. This leads to a greater energy input in the mean temperature scenario compared to the maximum temperature scenario and to a faster snowmelt.

The average date of snowmelt in the rock and sward habitat zones moves forward by up to a month for an average temperature increase of close to $4 \mathrm{~K}$. The strongest decrease in the snow cover duration occurs in the lower elevation parts of the investigated area and on the south-exposed slopes (Figure 5), thus clearly demonstrating the influence of direct solar energy. Furthermore, the pattern of snowmelt differs quite strongly between the minimum and the maximum temperature scenario, especially the number of days with a thin snow cover decreases. This is due to the fact that, for lower altitudinal classes, the negative hourly temperature anomalies compared to the baseline period (1978-1998) used to construct the scenario, already exceed the freezing point in some instances and therefore the warming does not have as important an impact as for the highest altitudinal classes. Therefore, the effect of the minimum temperature scenario is conspicuous for the highest altitudinal classes.

In the maximum temperature scenario, only the positive hourly temperature anomalies are increased and therefore the negative anomalies can still occur well below the freezing point, thereby increasing the daily temperature range and the rate of snowmelt. That is why in all altitudinal classes the model simulates a larger 
number of days with a snow depth below $25 \mathrm{~cm}$. This leads to large differences in the spatial melting pattern between the maximum and the minimum temperature scenario. In the maximum temperature scenario, the additional energy that this scenario implies can be fully used to melt the snow (i.e. increase of the positive anomalies), whereas in the minimum temperature scenario it is used to increase the temperature of the negative anomalies up to and above the freezing point. For example, 53 days more above freezing point could be counted when the minimum temperature scenario was compared to control temperature values.

It could be argued that temperature and precipitation are correlated, and hence a change in one parameter is accompanied by a change in the other and both variables should always be simulated together. For this study a combination of both parameters (temperature and precipitation) is producing a negligible synergy in the simulation of the snow depth and duration (Mölders, 2000). Also, the correlation between temperature and precipitation depends on the timescale. Short-term (daily to yearly) variations tend to be negatively correlated, but long-term correlations may be positive or negative. Therefore, for decadal-scale changes in climate, it is valid to treat changes in temperature and precipitation separately.

The simulated snowmelt results presented here are similar to the results obtained using different methods applied to other locations. Studies of Martin et al. (1994), Bultot et al. (1994), Whetton et al. (1996) and Beniston (1997) showed a marked sensitivity of simulated snow cover duration to increasing temperature, with the strongest sensitivity at low elevation sites. The study of Martin et al. (1994) also examined the impact of variations in precipitation of $10 \%$ and, in agreement with the current study, found snow cover duration to be rather insensitive to such variations. Brown (2000) and Ye et al. (1998) observed an increased snow accumulation during cold months and reduced snow accumulation in spring in the 20th century. However, not all studies investigate the impact of a combined temperature and precipitation scenario which, according to the current analysis, introduces a negligible nonlinearity effect (see also Beniston et al., 2003a).

However, all these studies consider much larger spatial scales. The challenge to simulate snowmelt at very fine scales relevant for plant life requires a specific knowledge of snowmelt patterns at particular locations. In our case, we found that the general spatial pattern of snowmelt always remains the same but, depending on the scenarios considered, the date of snowmelt changes. This confirms observations by Friedel (1961 in Körner, 1999) who determined spatially conservative snowmelt figures in alpine terrain for which snow depth and timing of melting change from year to year and thus determine plant distribution. However, if snowmelt were always to occur earlier in a future climate, some areas would always be snowfree earlier. These areas could be invaded by species potentially better able to flower at shorter day length than the species present on the patch. The species for which snowmelt occurs too early might attempt to find a higher refugia. Speciesspecific growth schedules and phenology will change the plant composition in these small-scale habitats. Galen and Stanton (1995) also concluded that interspecific 
differences in growth phenology of coexisting species would promote shifts in snowbed plant communities. They show that such changes in plant communities are anticipated when neighboring species differ in sensitivity to environmental changes, such as the preference for a specific day length at snowmelt, for example. Most advances in snowmelt date in the defined habitat zones could be observed in this study in the rock and sward zones. Opportunistic species which grow in these zones like Minuartia sedoides, Poa alpina, Ranuncula glacialis and Saxifraga seguieri (Table I) might be potentially able to flower more in these areas at earlier moments in the year. As Gottfried et al. (1998) have noted, high altitude specialist species, if widespread (like Androsace alpina) will reach such refugia habitats; but rare species will probably become extinct on some mountains. Dirnböck et al. (2003) support the hypothesis that alpine plant species with restricted habitat availability will experience severe fragmentation and habitat loss. They showed that this would only occur if temperatures increase by $2 \mathrm{~K}$ or more. On the other hand, Pauli et al. (1999) have already observed an increase in species numbers on mountains with increased ridge topography, which apparently act as migration corridors.

Despite a number of limitations, this study nevertheless demonstrates the sensitivity of the snowmelt patterns to different temperature and precipitation scenarios and shows its possible impact on vegetation habitat zones at this high altitude site.

\section{Conclusion}

This study describes considerable changes in snowmelt timing and snow amount on a fine-scale relief according to a number of regional climate change scenarios. Following the investigated scenarios, five defined plant habitat zones (snowbed, ridge, scree, sward, rock) will be partly snow-free earlier in the year than under current climatic conditions. With respect to photoperiodic preferences, not all species are potentially able to flower at earlier moments in the year. In the rock, scree, and sward zones, snow melts much earlier for the mean temperature, maximum temperature and combined mean temperature and precipitation scenario, allowing potential flowering by 3 April of $81 \%$ of sward-zone plants, $71 \%$ of scree-zone plants and all rock zone-plants. Therefore, a possible consequence of snowmelt always occurring earlier in the year is a modification of the species composition of these plant habitat zones. The species that are able to cope with the changed environmental conditions might become more abundant.

Although the snow pack parameterization in the present study is a rather simple, the approach used shows that a SEBM distributed onto a fine mesh covering a small area is a valuable technique to assess the snow cover variation under specific temperature and precipitation changes. However, the results of this study are valid for a particular area and the applicability of this approach is limited to areas where adequate meteorological data and a fine-scaled DEM are available. The rather 
coarse horizontal resolution of the climate change scenarios imply the necessity for improved downscaling and modeling approaches to adequately address the issues of climate change on fine scale environments such as mountain ecosystems.

\section{Acknowledgments}

The authors would like to thank Prof. Ch. Körner for commenting on an earlier draft of the manuscript and an anonymous reviewer.

\section{Appendix}

\section{MODEL STRUCTURE AND PARAMETERIZATION}

The SEBM used in this study is driven by time series of input data symbolized by $\Psi_{\mathrm{i}}=\left\{T, T_{\mathrm{d}}, v, P, K \downarrow, p\right\}$, where $T$ and $T_{\mathrm{d}}$ represent the observed air and dew point temperature, both measured at the screen level $(\mathrm{K}), v$, is the anemometer-level horizontal wind speed $\left(\mathrm{m} \mathrm{s}^{-1}\right), P$ is the precipitation rate $\left(\mathrm{mm} \mathrm{s}^{-1}\right), K \downarrow$, the net incoming solar radiation $\left(\mathrm{W} \mathrm{m}^{-2}\right)$, and $p$, the surface pressure $(\mathrm{Pa})$. The simulated snow cover, resulting from the energy and water balance at the surface, is modeled as a pack with a temperature, $T_{\text {snow }}$, a mass, $M_{\text {snow }}$, and a density of $\rho_{\text {snow }}$. Details of the parameterization schemes are found in Keller and Goyette (accepted). Compared to the methodology developed in that paper, the model has been upgraded in such a way as to simulate the impact of solar radiation on surfaces inclined at different angles and orientated in different directions according to Oke (1987), such that $K \downarrow$ is a function of the local slope $\alpha$ and orientation $\beta$.

\section{EXPERIMENTAL DESIGN}

The first part of this study aims at simulating the change in the duration of snow cover with a SEBM over a small area close to the Säntis weather station and in response to three simple climate-warming scenarios. For this study, it is assumed that the observed data is homogeneous in the horizontal, given that the surface area covered by the grid is relatively small. However, these data is modulated in such a way that for each of the pixels belonging to the surface grid, the time series of effective input data, $\Psi_{\mathrm{i}}$, needed by the model is computed as the sum of observed values, $\Psi_{\mathrm{i}, \text { obs }}$, and an altitudinal adjustment, $\Delta_{1} \Psi_{\mathrm{i} \text {,vint }}$, combined with an additional perturbation specific to each variable prescribed to emulate climate warming, $\Delta_{2} \Psi_{\mathrm{i} \text {, warm. }}$. Thus, the model-input data are computed as follows:

$$
\Psi_{\mathrm{i}}=\Psi_{\mathrm{i}, \mathrm{obs}}+\Delta_{1} \Psi_{\mathrm{i}, \text { vint }}+\Delta_{2} \Psi_{\mathrm{i}, \text { warm }}
$$


Consequently, the time series of effective input data provide a realistic representation of the current and future climate conditions over the area close to the Säntis station.

The vertical interpolation, $\Delta_{1}$, depends on the relative difference between the true altitude of the station, $z_{\mathrm{obs}}$, and that of individual grid points on the mesh, $z_{\mathrm{i}}$, such that $\Delta z=z_{\mathrm{obs}}-z_{\mathrm{i}}$. This difference is specific to each variable. The air temperature is interpolated in the vertical using the mean environmental lapse rate. The surface pressure varies in the vertical according to the Poisson equation $\left(T / T_{\mathrm{i}}\right)=\left(p / p_{\mathrm{i}}\right)^{\kappa}$, where $(p, T)$ represents the initial state compiled from observation, $\left(p_{\mathrm{i}}, T_{\mathrm{i}}\right)$ the final state onto the computational grid, and $\kappa=R / c_{\mathrm{p}} ; R$ is the gas constant for dry air $\left(287.04 \mathrm{~J} \mathrm{~kg}^{-1} \mathrm{~K}^{-1}\right)$, and $c_{\mathrm{p}}$ is the specific heat of air at constant pressure $\left(1004 \mathrm{~J} \mathrm{~kg}^{-1} \mathrm{~K}^{-1}\right)$. The dew point temperature is interpolated assuming a constant relative humidity profile in the vertical.

The altitudinal perturbations to the observed values of screen-level air temperature, dew-point temperature, and surface pressure, respectively $T_{\mathrm{obs}}, T_{\mathrm{d}}$,obs, and $p_{\text {obs }}$, are computed as follows:

$$
\begin{aligned}
\Delta_{1} T_{\text {vint }} & =\gamma \Delta \mathrm{z} \\
\Delta_{1} T_{\mathrm{d}, \text { vint }} & =T_{\mathrm{d}, \mathrm{obs}}-\left[\frac{1}{T}-\frac{R_{\mathrm{v}}}{L_{\mathrm{v}}} \ln h\right]^{-1} \\
\Delta_{1} p_{\text {vint }} & =p_{\mathrm{obs}}-p_{\mathrm{obs}}\left[\frac{T}{T_{\mathrm{obs}}}\right]^{g / \gamma R}
\end{aligned}
$$

where $\gamma$ is the vertical lapse rate defined as $6.5 \mathrm{~K} / \mathrm{km}, R_{\mathrm{v}}$ is the water vapor constant (461.5 $\left.\mathrm{J} \mathrm{kg}^{-1} \mathrm{~K}^{-1}\right), L_{\mathrm{v}}$ is the latent heat of vaporization $\left(2.5 \times 10^{6} \mathrm{~J} \mathrm{~kg}^{-1}\right), g$ is the constant of gravity $\left(9.80616 \mathrm{~m} \mathrm{~s}^{-2}\right)$. The relative humidity, $h$, derived from observations is computed as follows:

$$
h=\exp \left[\frac{L_{\mathrm{v}}}{R_{\mathrm{v}}}\left(\frac{1}{T_{\mathrm{obs}}}-\frac{1}{T_{\mathrm{d}}}\right)\right]
$$

The altitudinal perturbation to the precipitation, $P$, has been neglected mainly due to a lack of observational data to validate the precipitation lapse rate at the Säntis station. Some studies proposed a correction term allowing for the precipitation to increase linearly with height in the form: $\Delta_{1} P_{\text {vint }}=P_{\text {obs }}(1-\beta \Delta z)$ when $z_{\mathrm{i}}$ is higher than $z_{\mathrm{obs}}$, and equal to 0 when $z_{\mathrm{i}}$ is lower that $z_{\mathrm{obs}}$ (e.g., Liston et al., 1999). In this correction term, $\beta$ is a station-dependent parameter whose value has to be determined with care. Considering that the Säntis station is located at the top of the computational grid, the correction would indeed be negligible; consequently we considered $\Delta_{1} P_{\text {vint }}=0$.

For this study, the altitudinal perturbations of the wind speed and that of the incoming solar radiation are assumed to be zero, i.e., $\Delta_{1} v_{\text {vint }}=\Delta_{1} K \downarrow_{\text {vint }}=0$.

Next, to emulate the effect of a climate change scenario, a series of perturbations, $\Delta_{2}$, are combined with the screen air temperature and precipitation input data as 
TABLE V

Temperature changes for 2071-2100 for the mean (Mean), minimum (Min) and maximum (Max) temperature for each season according to Christensen (2002)

\begin{tabular}{lrlrl}
\hline & DJF & MAM & JJA & SON \\
\hline Mean (in K) & 3.25 & 3.23 & 4.60 & 4.74 \\
Min (in K) & 4.39 & 3.53 & 4.04 & 4.64 \\
Max (in K) & 2.66 & 3.32 & 5.31 & 5.15 \\
Pcp (in \%) & $+10 \%$ & No change & $-10 \%$ & No change \\
\hline
\end{tabular}

The precipitation scenario was deduced from Giorgi and Francisco (2000). DJF: December, January, February; MAM: March, April, May; JJA: June, July, August; SON: September, October, November. Pcp stands for precipitation.

described in Table V. For this study, the climate change perturbations of wind speed, surface pressure, and incoming solar radiation resulting from climate change are assumed to be zero, i.e., $\Delta_{2} v_{\text {warm }}=\Delta_{2} p_{\text {warm }}=\Delta_{2} K \downarrow_{\text {warm }}=\Delta_{2} T_{\text {dwarm }}=0$.

The temperature increase scenarios, $\Delta_{2} T_{\text {warm }}$, over Switzerland are based on results from the HIRHAM regional climate model available to us in the context of the EU 5th Framework Program PRUDENCE project (Christensen et al., 2002). These simulations are based on the global greenhouse-gas emission A2 established by the IPCC (Nakicenovic et al., 2000) which lies within the upper bounds of the IPCC scenarios. The driving General Circulation Model (GCM) for these simulations is the UK Hadley Center's HADCM3 coupled ocean-atmosphere model.

The reference period was 12 months from September 1988 to August 1989. This was a period in which the snow data were complete. Seasonal warming scenarios were calculated for mean, minimum and maximum temperature (Table V). The mean temperature scenario indicates a general increase of the observed temperature of the reference period. To construct the minimum and the maximum temperature scenarios, the negative hourly and positive hourly anomalies of the reference period in comparison to the hourly observations of the baseline period 1978-1998 were respectively increased in such a way that they reach the seasonal values of the scenarios as shown in Table V. For the minimum temperature scenario only the negative hourly anomalies are increased, which results in a decrease of the daily temperature range. The maximum temperature scenario shows an increase of the positive hourly anomalies that leads to an increase of the daily temperature range (Figure 6). The scenarios are seasonal averages for 2071-2100 and assume that the $\mathrm{CO}_{2}$-emissions increase from $7.97 \mathrm{PgC} / \mathrm{yr}(\approx 370 \mathrm{ppm})$ in 2000 to 29.09 $(\approx 800 \mathrm{ppm})$ in 2100 what corresponds to the IPCC A2 scenario. Furthermore, a scenario for precipitation is constructed on the basis of Giorgi and Francisco (2000) where each already existing precipitation event is increased by $10 \%$ in intensity in 


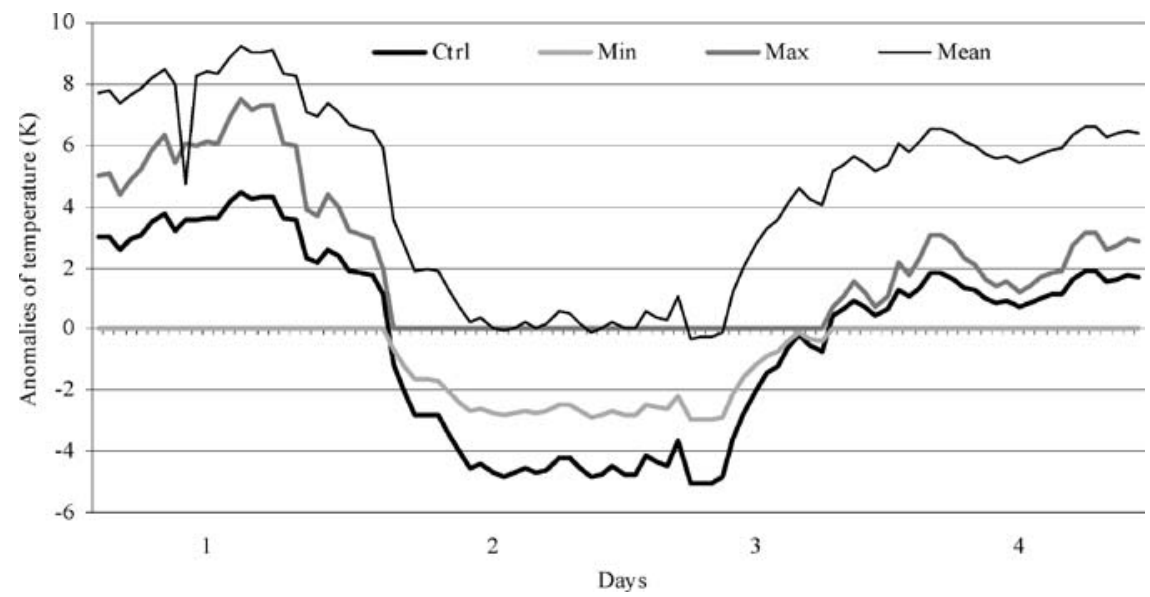

Figure 6. Illustration of the construction of the temperature scenarios. $\Delta$ Mean, $\Delta$ Min and $\Delta$ Max indicate the respective seasonal increase for the respective temperature scenario.

the winter months (December, January, February) and decreased by $10 \%$ during the summer months (June, July, August). In spring and autumn the precipitation amounts remain the same. In a final scenario the mean temperature scenario is combined with the precipitation scenario to examine their mutual effects (Beniston et al., 2003a). For each grid point on the mesh within the study area, a separate simulation is achieved using $\Psi_{\mathrm{i}}$ as effective input data for the SEBM model.

\section{References}

Bahn, M. and Körner, Ch.: 1987, 'Vegetation und Phänologie der hochalpinen Gipfelflur des Glungezer in Tirol', Ber. Nat.-Med. Verein Innsbruck, 74, 61-80.

Bantle, H.: 1989, Programmdokumentation Klima-Datenbank am RZ-ETH Zürich, Schweizerische Meteorologische Anstalt, Zürich.

Beniston, M., Fox, D. G., Adhikary, S., Andresson, R., Guisan, A., Holten, J. I., Maitima, J., Price, M., and Tessier, L. E.: 1996, 'The impacts of climate on mountain regions. Second assessment report of the intergovernmental panel on climate change (IPCC)', Ch. 5, Cambridge University Press, Cambridge, U.K.

Beniston, M.: 1997, 'Variation of snow depth and duration in the Swiss Alps over the last 50 years: Links to changes in large-scale climatic forcing', Clim. Change 36, 281-300.

Beniston, M., Diaz, H. F., and Bradley, R. S.: 1997, 'Climatic change at high elevation sites: An overview', Clim. Change 36, 233-251.

Beniston, M., Keller, F., and Goyette, S.: 2003a, 'Snow pack in the Swiss Alps under changing climatic conditions: an empirical approach for climate impacts studies', Theor. Appl. Clim. 74, 19-31.

Beniston, M., Keller, F., Koffi, B., and Goyette, S.: 2003b, 'Estimates of snow accumulation and volume in the Swiss Alps under changing climatic conditions', Theor. Appl. Clim. 76, 125-140.

Billings, W. D. and Bliss, L. C.: 1959, 'An alpine snowbank environment and its effects on vegetation, plant development, and productivity', Ecology 40, 388-397.

Brown, R. D.: 2000, 'Northern hemisphere snow cover variability and change, 1915-97', J. Clim. 13, 2339-2355. 
Bultot, F., Gellens, D., Schädler, B., and Spreafico, M.: 1994, 'Effects of climate change on snow accumulation and melting in the Broye catchment (Switzerland)', Clim. Change 28, 339363.

Christensen, J. H., Carter, T. R., and Giorgi, F.: 2002, 'PRUDENCE employs new methods to assess European Climate Change', EOS 83(13), 147.

Dirnböck, T., Dullinger, S., and Grabherr, G.: 2003, 'A regional impact assessment of climate and land-use change on alpine vegetation', J. Biogeog. 30, 410-417.

Ehrendorfer, F.: 1973, 'Liste der Gefässpflanzen Mitteleuropas', Fischer, Stuttgart, p. 318.

Fischer, H. S.: 1990, 'Simulating the distribution of plant communities in an alpine landscape', Coenoses 5, 37-43.

Friedel, H.: 1961, 'Schneedeckendauer und Vegetationsverteilungen im Gelände', Mitt. Forstl. Bundes. Versuchsanst. Mariabrunn (Wien) 59, 317-369.

Galen, C. and Stanton, M. L.: 1995, 'Response of snowbed plant species to changes in growing season length', Ecology 76, 1546-1557.

Giorgi, F. and Francisco, R.: 2000, 'Evaluating uncertainties in the prediction of regional climate change', Geophys. Res. Lett. 27, 1295-1298.

Gottfried, M., Pauli, H., and Grabherr, G.: 1998, 'Prediction of vegetation patterns at the limits of plant life: A new view of the alpine-nival ecotone', Arct. Alp. Res. 30(3), 207-221.

Gottfried, M., Pauli, H., Reiter, K., and Grabherr, G.: 1999, 'A fine-scaled predictive model for changes in species distribution patterns of high mountain plants induced by climate warming', Divers. Distr. 5, 241-251.

Grabherr, G., Gottfried, M., Gruber, A., and Pauli, H.: 1995, 'Patterns and Current Changes in Alpine Plant Diversity', in Chapin, F. S. III and Körner, Ch. (eds.), Arctic and Alpine Biodiversity: Patterns, Causes and Ecosystem Consequences, Ecological Studies, vol. 113, Springer, Berlin Heidelberg, New York, pp. 167-181.

Guisan, A., Theurillat, J.-P., and Kienast, F.:1998, 'Predicting the potential distribution of plant species in an alpine environment', J. Veg. Sci. 9, 65-74.

Horsch, B.: 2003, 'Modelling the spatial distribution of montane and subalpine forests in the central Alps using digital elevation models', Ecol. Modell. 168(3), 267-282.

IPCC: 2001, Climate Change. The IPCC Third Assessment Report, Working Group I (The Scientific Basis), Cambridge University Press, Cambridge and New York, pp. 881.

Jones, P. D. and Moberg, A.: 2003, 'Hemispheric and large-scale surface air temperature variations: An extensive revision and an update to 2001', J. Clim. 16, 206-223.

Jungo, P. and Beniston, M.: 2001, 'Changes in the anomalies of extreme temperatures in the 20th century at Swiss climatological stations located at different latitudes and altitudes', Theor. Appl. Climatol. 69, 1-12.

Keller, F. and Goyette, S.: 'Snowmelt under the different temperature increase scenarios in the Swiss Alps', in de Jong, C., Collins, D. and Ranzi, R. (eds.), Climate and Hydrology in Mountain Areas, Wiley, U.K., accepted.

Keller, F. and Körner, Ch.: 2003, 'The role of photoperiodism in alpine plant development', Arct. Antarct. Alp. Res. 35(3) 361-368.

Körner, Ch.: 1992, 'Response of alpine vegetation to global climate change', Catena Suppl. 22, 85-68.

Körner, Ch.: 1994, 'Impact of atmospheric changes on high mountain vegetation', in Beniston, M. (ed.), Mountain Environments in Changing Climates, Routledge, London, pp. 155-166.

Körner, Ch.: 1995, 'Alpine plant diversity: A global survey and functional interpretations', in Chapin, F. S. III and Körner, Ch. (eds.), Arctic and Alpine Biodiversity: Patterns, Causes and Ecosystem Consequences, Springer, Berlin, pp.45-62.

Körner, Ch.: 1999, Alpine Plant Life: Functional Plant Ecology of High Mountain Ecosystems, Springer, Berlin Heidelberg, p. 343.

Körner, Ch. and Larcher, W.: 1988, 'Plant life in cold climates', Symp. Soc. Exp. Biol. 42, 25-57. 
Lauber, K. and Wagner, G.: 1996, 'Flora Helvetica, Flora der Schweiz, Flore de la Suisse, Flora della Svizzera', Haupt, Bern, p. 1613.

Liston, G. E., Pielke Sr, R. A., and Greene, E. M.: 1999, 'Improving first-order snow-related deficiencies in a regional climate model', J. Geophys. Res. 104(D16), 19559-19567.

Martin, E., Brun, E., and Durand, Y.: 1994, 'Sensitivity of the French Alps snow cover to the variation of climatic variables', Ann Geophys 12, 469-477.

Mölders, N.: 2000, 'Application of the principle of superposition to detect nonlinearity in the shortterm atmospheric response to concurrent land-use changes associated with future landscapes', Meteor. Atmos. Phys. 72, 47-68.

Nakicenovic, N., Alcamo, J., Davis, G., de Vries, B., Fenhann, J., Gaffin, S., Gregory, K., Grübler, A., Jung, T. Y., Kram, T., La Rovere, E. L., Michaelis, L., Mori, S., Morita, T., Pepper, W., Pitcher, H., Price, L., Raihi, K., Roehrl, A., Rogner, H-H., Sankovski, A., Schlesinger, M., Shukla, P., Smith, S., Swart, R., van Rooijen, S., Victor, N., and Dadi, Z.: 2000, 'IPCC Special Report on Emissions Scenarios', Cambridge University Press, Cambridge, United Kingdom and New York, NY, U.S.A., p. 599.

Oke, T. R.: 1987, Boundary Layer Climates, Routledge, London, p. 435.

Pauli, H., Gottfried, M., and Grabherr, G.: 1999, 'Vascular plant distribution patterns at the lowtemperature limits of plant life - The Alpine-nival ecotone of Mount Schrankogel (Tyrol, Austria)', Phytocoenologia 29(3), 297-325.

Theurillat, J. P. and Guisan, A.: 2001, 'Potential impact of climate change on vegetation in the European Alps: A review', Clim. Change 50, 77-109.

Whetton, P. H., Haylock, M. R., and Galloway, R.: 1996, 'Climate change and snow-cover duration in the Australian Alps', Clim. Change 32, 447-479.

Ye, H., Cho, H. R., and Gustafson, P. E.: 1998: 'The changes in Russian winter snow accumulation during 1936-83 and its spatial patterns', J. Clim. 11, 856-863. 